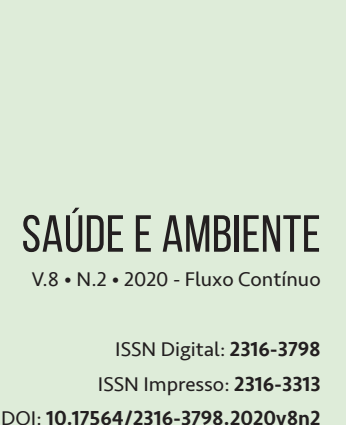

DOI: $10.17564 / 2316-3798.2020 v 8 n 2$

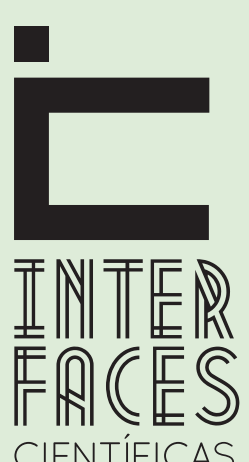

\section{ANÁLISE DOS PARÂMETROS DE QUALIDADE DA ÁGUA DE POÇO EM CONDOMIINIONA CIDADE DE SÃO LUÍS / MA}

\section{ANALYSIS OF WELL WATER QUALITY PARAMETERS IN CONDOMINIUM IN THE CITY OF SÃO LUIS / MA}

\section{ANÁLISIS DE LOS PARÁMETROS DE CALIDAD DEL AGUA DE POZO EN UN CONDOMINIO EN LA CIUDAD DE SÃO LUÍS/MA}

\section{RESUMO}

Atualmente, as águas subterrâneas têm sido objeto de exploração por diferentes usuários, entre eles os condomínios residenciais, dado principalmente pela falta de água nas redes de abastecimento em certos períodos do dia e pela facilidade de exploração por meio de poços. Com base nesta premissa, o objetivo do presente trabalho foi avaliar a qualidade da água subterrânea utilizada em um condomínio residencial abastecido através de um poço localizado no próprio condomínio, por meio da análise de parâmetros físico-químicos e microbiológicos, realizados no laboratório de $\mathrm{Ci}$ ências do Ambiente da Universidade CEUMA, onde foram estudados os parâmetros $\mathrm{pH}$, turbidez, salinidade, condutividade elétrica e sólidos totais dissolvidos. Para a análise microbiológica foi avaliada a presença da bactéria do tipo coliforme (Escherichia coli), sendo os resultados obtidos comparados à valores indicativos da portaria no 2914/2011 do Ministério da Saúde. O estudo concluiu que os parâmetros físico-químicos se encontram dentro do padrão permitido, diferentemente do bacteriológico, o qual identificou a contaminação da água do poço pela bactéria $E$. coli, principal indicador que comprova a contaminação fecal. Sendo assim, a água utilizada no referido condomínio, nas atividades diversas pelos moradores, encontra-se inadequada ao consumo humano devido à presença de bactéria do grupo coliforme, a qual quando ingerida pode provocar inúmeras enfermidades.

\section{PALAVRAS-CHAVE}

Qualidade de água, Manancial subterrâneo, Abastecimento público, Análise físico-química e bacteriológica. 


\section{ABSTRACT}

Currently, groundwater has been the object of exploitation by different users, among them residential condominiums, mainly due to the lack of water in the supply networks at certain times of the day and the ease of exploration by means of wells. Based on this premise, the objective of the present study was to evaluate the quality of groundwater used in a residential condominium that is supplied through a well located in the condominium itself, through the analysis of physicochemical and microbiological parameters, Environment of the CEUMA University, where the parameters $\mathrm{pH}$, turbidity, salinity, electrical conductivity and total dissolved solids were studied. The presence of coliform bacteria (Escherichia coli) was evaluated for the microbiological analysis, and the results obtained were compared to the values indicated in Ministry of Health Ordinance 2914/2011. The study concluded that the physical-chemical parameters are within of the permitted standard, differently from the bacteriological one, which identified the well water contamination by the bacterium E. coli, the main indicator that proves the fecal contamination. Therefore, the water used in this condominium, in the diverse activities by the residents, is inadequate to human consumption due to the presence of bacteria of the coliform group, which when ingested can cause innumerable diseases.

\section{KEYWORDS}

Water Quality, Underground Fountain, Public Supply, Physical-Chemical and Bacteriological Properties.

\section{RESUMEN}

Actualmente, el agua subterránea ha sido objeto de explotación por parte de diferentes usuarios, entre ellos condominios residenciales, principalmente debido a la falta de agua en las redes de suministro en ciertos momentos del día y la facilidad de exploración por medio de pozos. Basado en esta premisa, el objetivo del presente estudio fue evaluar la calidad del agua subterránea utilizada en un condominio residencial que se suministra a través de un pozo ubicado en el propio condominio, a través del análisis de parámetros fisicoquímicos y microbiológicos, Ambiente de la Universidad CEUMA, donde se estudiaron los parámetros $\mathrm{pH}$, turbidez, salinidad, conductividad eléctrica y sólidos disueltos totales. La presencia de bacterias coliformes (Escherichia coli) se evaluó para el análisis microbiológico, y los resultados obtenidos se compararon con los valores indicados en la Ordenanza 2914/2011 del Ministerio de Salud. El estudio concluyó que los parámetros físicoquímicos están dentro de del estándar permitido, a diferencia del bacteriológico, que identificó la contaminación del agua del pozo por la bacteria E. coli, el principal indicador que demuestra la contaminación fecal. Por lo tanto, el agua utilizada en este condominio, en las diversas actividades de los residentes, es inadecuada para el consumo humano debido a la presencia de bacterias del grupo de coliformes, que cuando se ingieren pueden causar innúmeras enfermedades. 


\section{PALABRAS CLAVE}

Calidad del agua, Fuente subterránea, Abastecimiento público, Análisis físico-químicos y bacteriológicos

\section{INTRODUCÇÃO}

A água cobre cerca de $70 \%$ da superfície terrestre. Apesar de sua abundância, a água considerada própria ao consumo está cada vez mais escassa. A água doce apropriada para uso ao abastecimento humano corresponde a apenas $2,5 \%$ do total mundial e menos de $1 \%$ está em condições adequadas e em depósitos acessíveis ao homem (VIEIRA, 2006).

O Brasil, no cenário mundial, é visto como um dos países que apresenta uma das maiores reservas disponíveis de água doce do planeta. Porém, grande parte desse recurso está concentrada em regiões onde há menor densidade humana. Nos grandes centros urbanos há elevada densidade populacional e forte demanda pelos recursos hídricos que, em muitos casos, são atingidos pela poluição e, por consequência, há uma piora considerável na sua qualidade, tornando o abastecimento nas cidades e regiões metropolitanas um grande desafio (ANA, 2006).

Água potável é toda água própria para o consumo. É tida como um líquido incolor, inodoro (sem cheiro), insípida (sem sabor) e insossa (sem sal), essencial para a sobrevivência humana. Deve apresentar certa quantidade de sais minerais dissolvidos, que são importantes para a saúde principalmente humana. Além disso, ela deve estar livre de materiais tóxicos e da presença de micro-organismos, tais como bactérias, protozoários etc., que contribuem para a transmissão de doenças como cólera, salmonelose, shiguelose e gastrenterites causadas por Escherichia coli, especialmente em crianças e imucomprometidos, fato que resulta em ônus para os países em desenvolvimento (HLAVSA et al., 2011).

Uma água de qualidade duvidosa pode ser responsável por causar, muitas vezes, inúmeras enfermidades a quem a consome, dentre elas as infecções gastrointestinais, assim a necessidade de água de qualidade é o propósito primário para a proteção da saúde do homem e das populações (PALUDO, 2010).

Os países desenvolvidos conseguem atender, na maioria das vezes, as necessidades de suas populações por meio de sistemas coletivos de distribuição que possibilitam o acesso adequado à água potável para todos. Por outro lado, os países em desenvolvimento como o Brasil e, em especial, regiões mais desfavorecidas, como é o caso das regiões Norte e Nordeste, apresentam parcelas significativas de sua população urbana e rural sem acesso ou com um acesso precário à água potável (NOGUEIRA et al., 2003).

De acordo com orientações do Manual de Controle da Qualidade da Água estabelecido pela Fundação Nacional de Saúde - FUNASA (BRASIL, 2014), para caracterizar uma água são determinados diversos parâmetros, que são indicadores da qualidade da água e se constituem não conformes quando alcançam valores superiores aos estabelecidos para determinado uso.

As características físicas, químicas e biológicas da água estão associadas a uma série de processos que ocorrem no corpo hídrico e em sua bacia de drenagem. Segundo Von Sperling (1996), a qua- 
lidade da água depende das condições naturais da bacia hidrográfica, bem como, das interferências do homem nessa bacia. Porém, para que uma água tenha qualidade desejável deve-se verificar qual será as atividades previstas para seu uso.

Com base nestas premissas, a pesquisa elaborada avaliou a qualidade da água captada de um poço localizado em um condomínio em São Luis-MA que é utilizada como fonte complementar ao abastecimento das unidades habitacionais existentes no local.

\section{METODOLOGIA}

A pesquisa foi realizada em um condomínio residencial, localizado no bairro Turu, na cidade de São Luís, estado do Maranhão, local este no qual o abastecimento complementar de água aos edifícios é realizado por meio de um poço artesiano, que alimenta os reservatórios de 12 torres, distribuindo assim a água para uso nestes apartamentos. Cada torre residencial pertencente ao condomínio é composta de 16 apartamentos, totalizando assim 192 unidades habitacionais.

No bairro, há o abastecimento de água potável pela concessionária local, entretanto, em função do mal funcionamento do sistema atual existente, o condomínio assim como muitas residências da região utilizam-se também da água subterrânea extraída de poços para suas atividades cotidianas, como complemento à fonte existente. Para efeito de estudo no condomínio, a água foi coletada em um ponto de derivação do poço que complementam o abastecimento das unidades residenciais, exatamente no intuito de identificar a qualidade da água subterrânea extraída e usada pelos moradores locais em suas atividades cotidianas.

A Figura 1 permite visualizar a área ocupada pelo condomínio e suas torres, que equivale a cerca de $12.717 \mathrm{~m}^{2}$ de área construída e uma população total estimada de 960 moradores.

Figura 1 - Área do Condomínio Estudado na cidade de São Luís, Maranhão

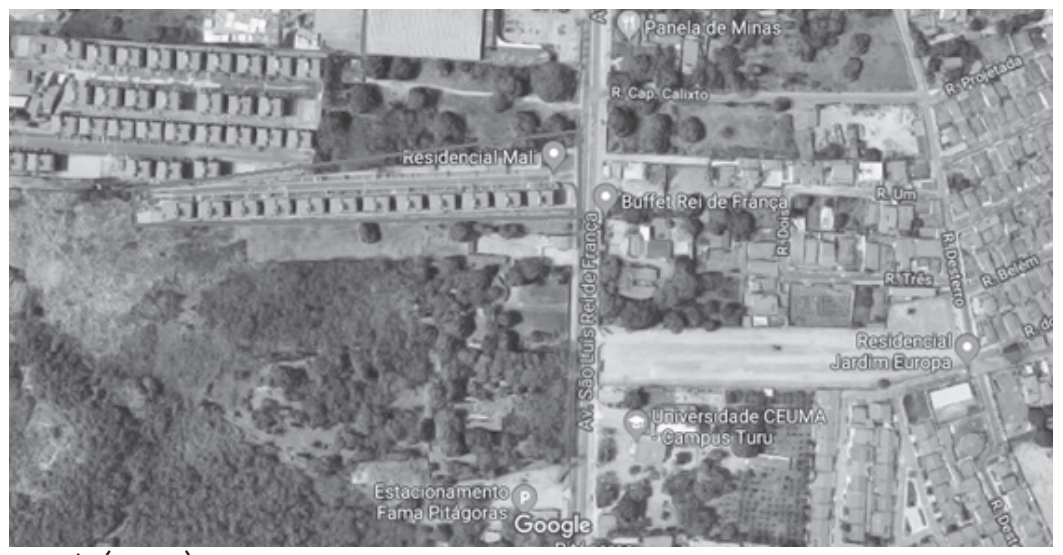

Fonte: Google Earth (2019). 
O procedimento metodológico utilizado contemplou a coleta de amostra de água e a análise das propriedades físico-químicos e bacteriológica, seguindo as recomendações da American Public Health Association (APHA, 2012).

Os parâmetros analisados foram o potencial hidrogeniônico, $\mathrm{pH}$, medido pelo pHgâmetro e a turbidez medida com o turbidímetro. A condutividade elétrica, sólidos totais dissolvidos assim como a salinidade, foram medidos com equipamento multiparâmetro.

$\mathrm{Na}$ análise bacteriológica, ao material coletado foi adicionado o meio de cultura Colitest ${ }^{\circledR}$, sendo feita homogeneização e acondicionamento do material em caixa de isopor com gelo, para posterior envio ao laboratório.

Vale ressaltar que, antes da realização dos testes, em laboratório, todos os equipamentos foram checados para verificar se estavam calibrados, a fim de evitar qualquer interferência aos resultados obtidos na análise da amostra coletada.

Para a análise bacteriológica foi utilizado frasco esterilizado com $10 \mathrm{mg}$ de tiossufato de sódio e o kit Colitest ${ }^{\circledR}$. Em laboratório, a amostra de água coletada foi incubada em uma estufa a $37^{\circ} \mathrm{C}$ por 24 horas. A leitura da amostra para presença da bactéria Escherichia coli (E. coli) foi feita com luz Ultra Violeta (UV), sendo a coloração violeta positivo (indicativo da presença da bactéria). No estudo foi utilizado o meio seletivo BEM (isolamento de enterobactérias) para cultivo de amostras positivas para coliformes totais e E. coli, onde foi quantificada em unidade formadora de colônia por mililitros (UFC/100 mL).

\section{RESULTADOS E DISCUSSÃO}

Os resultados obtidos das análises realizadas dos indicadores físico-químicos, para a amostra da água captada no poço localizado junto ao condomínio residencial, utilizada no estudo, são apresentados na Tabela 1.

Tabela 1 - Resultados da Análise dos Parâmetros Físico-Químicos

\begin{tabular}{|c|c|c|}
\hline \multicolumn{3}{|c|}{ ANÁLISE DA AMOSTRA } \\
\hline \multicolumn{2}{|c|}{ PARÂMETROS FísICO-QUÍMICOS } & VALORES DE REFERÊNCIA \\
\hline $\mathrm{pH}$ & 6,6 & $6,0 \mathrm{a} 9,5$ \\
\hline TURBIDEZ & 0 & $5 \mathrm{uT}$ \\
\hline TDS & $12,7 \mathrm{mg} / \mathrm{L}$ & $1000 \mathrm{mg} / \mathrm{L}$ \\
\hline SALINIDADE & $0,02 \%$ & $5 \%$ \\
\hline CONDUTIVIDADE & $26,6 \mu \mathrm{S} / \mathrm{cm}$ & $100 \mu \mathrm{S} / \mathrm{cm}$ \\
\hline
\end{tabular}

TDS - Sólidos Totais Dissolvidos

Fonte: Brasil (2011). 
O parâmetro $\mathrm{pH}$ da amostra estudada ficou dentro do valor permitido para consumo humano, segundo valor de referência da portaria no 2914/2011 do Ministério da Saúde (BRASIL, 2011), embora caracterize uma água levemente ácida. 0 parâmetro turbidez apresentou-se nulo, sendo o resultado encontrado inferior ao valor de referência para tal parâmetro de qualidade.

O valor encontrado para os sólidos dissolvidos totais (TDS) ficou bem abaixo do valor limite na portaria enquanto que a presença do teor de sais, também apresentou resultado dentro do esperado para consumo humano. Por fim, o resultado da análise da condutividade elétrica também encontra-se dentro dos padrões de potabilidade.

Com relação à análise bacteriológica, na água captada do poço que abastece o condominio residencial foi identificada a presença da bactéria E.coli, de acordo com resultado apresentado na Tabela 2, indicando que a população do condomínio ao utilizar da água do poço em suas atividades diárias tem grande probabilidade de contrair doenças de veiculação hídrica.

Tabela 2 - Resultados da Análise do Parâmetro Bacteriológico

\begin{tabular}{|c|c|c|}
\hline \multicolumn{3}{|c|}{ ANÁLISE DA AMOSTRA } \\
\hline \multicolumn{2}{|c|}{ PARÂMETROS BACTERIOLÓGICOS } & VALORES DE REFERÊNCIA \\
\hline $\begin{array}{c}\text { Coliforme fecal ou termotolerantes } \\
\text { (Escherichia coli) }\end{array}$ & $2500 \mathrm{UFC} / 100 \mathrm{ml}$ & Ausência \\
\hline
\end{tabular}

TDS - Sólidos Totais Dissolvidos

Fonte: Dados da pesquisa

Embora não sejam patogênicas, a presença dessas bactérias (E. coli) na água indica que ela recebeu matéria fecal e pode, portanto, conter microrganismos patogênicos. Entre as bactérias do grupo coliforme, a mais usada como indicadora da poluição fecal é a Escherichia coli.

Os coliformes fecais são usados como indicadores da presença potencial de organismos patogênicos de origem fecal na água porque existem em grande número na matéria fecal e não existem em nenhum outro tipo de matéria orgânica poluente; por conseguinte, são indicadores específicos de matéria fecal.

Além disso, algumas das bactérias pertencentes ao grupo (Escherichia coli, por exemplo), não se reproduzem na água ou no solo, mas exclusivamente no interior do intestino (ou em meios de culturas especiais a certa temperatura adequada); portanto, só são encontradas na água quando nela for introduzida matéria fecal e seu número é proporcional à concentração dessa matéria.

Por fim, apresentam um grau de resistência ao meio (à luz, ao oxigênio, ao cloro e a outros agentes destruidores de bactérias) comparável ao que é apresentado pelos principais patogênicos intestinais que podem ser veiculados pelas águas, dessa maneira, reduz-se a possibilidade de existirem patogênicos fecais quando já não se encontram coliformes.

De acordo com Braga (2013), a presença de organismos patogênicos na água tais como a E. colipodem provocar doenças que podem causar incapacidade temporária ou mesmo a morte, sendo responsáveis por boa parte da ocupação dos leitos hospitalares e pela diminuição da qualidade de vida das pessoas. 


\section{CONCLUSÃO}

Com os resultados obtidos por meio dos testes e dos parâmetros analisados, conclui-se que a água do poço artesiano, que abastece o condomínio residencial, está inadequada para o consumo humano, pois a fonte de distribuição possui agentes contaminantes que permitem a ocorrência de doenças de vínculação hídrica, representando assim risco à saúde dos consumidores de água deste manancial subterrâneo. A água desse poço, no quesito bacteriológico, não se enquadra aos padrões de qualidade, segundo a portaria no 2914/2011 do Ministério da Saúde (BRASIL, 2011).

A possível causa da contaminação na água do poço pode ser devido a presença de um sumidouro, localizado próximo a fonte subterrânea, onde são lançados os esgotos in natura produzidos pelas 192 unidades habitacionais do conjunto residencial. Em função da presença de E.coli detectada na água do poço, foi comunicado à administração do condomínio tal fato, dado que a presença deste indicador aponta para a provável existência de patógenos na água. Isso reafirma a importância do controle microbiologico da água fornecida à população para prevenção de surtos de doenças, bem como a importância da prática de tratamento de água de poços, como a cloração, visando a prevenção da saúde coletiva.

\section{REFERÊNCIAS}

APHA - American Public Health Association. Standard methods for the examination of water and wastewater. $22^{\text {nd }}$ ed., Washington: American Public Health Association Pub., 2012.

ANA - Agência Nacional de Águas; Fundação Roberto Marinho. Caminho das Águas. Rio de Janeiro: ANA; FRM, 2006.

BRAGA, B. Qualidade das águas e tratamento de efluentes. São Paulo: Pearson Education do Brasil, 2013.

BRASIL. Ministério da Saúde. Portaria nº 291412 de dezembro de 2011. Dispõe sobre os procedimentos de controle e de vigilância da qualidade da água para consumo humano e seu padrão de potabilidade. Brasília: MS. 2011

BRASIL. Ministério da Saúde, Fundação Nacional de Saúde. Manual de controle da qualidade da água para técnicos que trabalham em ETAS. Brasília: Funasa. 2014.

HLAVSA, M. C. et al. Surveillance for waterborne disease outbreaks and other health events associated with recreational water --- United States, 2007--2008. MMWR Surveill. Summ., v. 60, n. 12, p. 1-32, 2011 
NOGUEIRA, G. et al. Microbiological quality of drinking water of urban and rural communities, Brazil. Rev. Saúde Publ., v. 37, n. 2, p. 232-236, 2003.

\section{PALUDO, D. Qualidade da água nos poços} artesianos do município de Santa Clara do Sul.

2010. 75f. Monografia (Graduação) - Centro

Universitário Univates, Lajeado, 2010.

\section{VIEIRA, A. R. Cadernos de educação ambiental} água para vida - água para todos: Livro das Águas. Brasília: WWF-Brasil, 2006.

\section{VON SPERLING, M. Introdução à qualidade das} águas e ao tratamento de esgotos. 2. ed. Belo Horizonte: Departamento de Engenharia Sanitária e Ambiental, Universidade Federal de Minas Gerais. 1996.

1 Professor do Curso de Engenharia Civil da Universidade CEUMA - UniCEUMA. Brasil - Mestre em Engenharia Civil. rcboni71@gmail.com

2 Acadêmico do Curso de Engenharia Civil da Universidade CEUMA - UniCEUMA. E-mail: jaedro@gmail.com

3 Acadêmico do Curso de Engenharia Civil da Universidade CEUMA - UniCEUMA. E-mail: madsonguilherme09@ hotmail.com

4 Acadêmico do Curso de Engenharia Civil da Universidade CEUMA - UniCEUMA. E-mail: oliveirarayane@gmail.com

Recebido em: 30 de Março de 2018

Avaliado em: 5 de Maio de 2018

Aceito em: 10 de Agosto de 2018

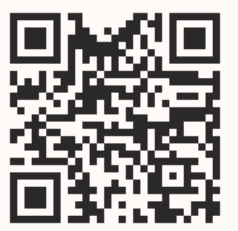

A autenticidade desse artigo pode ser conferida no site https://periodicos. set.edu.br

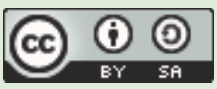

Este artigo é licenciado na modalidade acesso abertosob a Atribuição-Compartilhalgual CC BY-SA

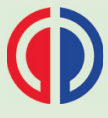

GRUPO TIRADENTES Inspirando o futuro

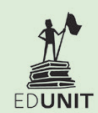

